\title{
PENERAPAN USABILITY TESTING TERHADAP SISTEM INFORMASI PENYEBARAN PENYAKIT UNGGAS
}

\author{
Nahdhatuzzahra1, Irwan Budiman², Dodon T. Nugrahadi ${ }^{3}$ \\ 1,2,3Prodi Ilmu Komputer FMIPA ULM \\ Jl. A. Yani Km 36 Banjarbaru, Kalimantan Selatan \\ 1Email: nahdhatuzzahra@gmail.com
}

\begin{abstract}
Efficiency and ease of an information system is a very important thing in any information system implementation. Prevention information system is an information system that is used to assist the relevant agencies, farmers and the general public to reduce the impact of outbreaks and reduce the possibility of spread of the disease in a particular region. Thus the effectiveness and convenience of an information system would be necessary so that information systems can be used easily and provide information that can be used to reduce the adverse effects spread of livestock disease and its treatments. This system aims to determine how much comparative efficiency and ease of deployment of information systems prevention of disease in poultry compared to systems that exist today. Usability testing is used to measure the efficiency and convenience of the system. With the spread of disease information system of poultry, can facilitate employee performance and provide information to the public.
\end{abstract}

Keywords: Poultry, Usability Testing, Web

\begin{abstract}
Abstrak
Efisiensi dan kemudahan dalam sebuah sistem informasi adalah hal yang sangat penting dalam setiap pembuatan sistem informasi. Sistem informasi penanggulangan adalah sebuah sistem informasi yang digunakan untuk membantu bagian dinas terkait, peternak dan masyarakat umum untuk mengurangi dampak penyebaran wabah serta mengurangi kemungkinan terjadinya penyebaran penyakit di wilayah tertentu. Maka dari itu efektivitas dan kemudahan sebuah sistem informasi akan sangat diperlukan agar sistem informasi dapat digunakan dengan mudah dan memberikan informasi yang dapat digunakan untuk mengurangi dampak buruk penyebaran penyakit ternak serta penanganannya. Sistem ini bertujuan untuk mengetahui seberapa besar perbandingan efisiensi dan kemudahan sistem informasi penanggulangan penyebaran penyakit pada ternak unggas dibandingkan dengan sistem yang ada saat ini. Usability testing digunakan untuk mengukur tingkat efisiensi dan kemudahan sistem ini. Dengan adanya sistem infomasi penyebaran penyakit ternak unggas, dapat mempermudah kinerja pegawai dan memberikan informasi kepada masyarakat.
\end{abstract}

Kata kunci: Ternak Unggas, Usability Testing,Web 


\section{PENDAHULUAN}

Efisiensi dan kemudahan dalam sebuah sistem informasi adalah hal yang sangat penting, dalam setiap pembuatan sistem informasi maupun aplikasi yang dapat digunakan secara umum oleh sebuah perusahaan, departemen pemerintahan maupun masyarakat umum sebaiknya memenuhi dua kriteria tersebut sehingga dapat dengan mudah diaplikasikan, dan benar-benar berguna sesuai dengan tujuan dibuatnya sistem informasi[1].

Efektivitas adalah tingkat pencapaian hasil program dengan target yang ditetapkan, secara sederhana efektivitas merupakan perbandingan tujuan dengan hasil yang dicapai [2].

Efektivitas dan kemudahan penggunaan sistem informasi tidak diputuskan berdasarkan banyak atau tidaknya pengguna, namun ketepatan hasil berdasarkan tujuan yang telah ditetapkan, yang pada akhirnya tujuan tersebut menghasilkan sebuah sistem informasi yang dapat membantu kerja individu maupun organisasi.

Efektivitas adalah tingkat pencapaian hasil program dengan target yang ditetapkan, secara sederhana efektivitas merupakan perbandingan tujuan dengan hasil yang dicapai [3]. Sehingga dalam pembuatan sebuah sistem informasi harus memiliki tujuan-tujuan yang telah ditetapkan sebelumnya dan saat sistem informasi selesai dibangun dilakukan evaluasi untuk membandingkan apakah sistem informasi yang dibangun sesuai dengan tujuan yang ditetapkan atau tidak.

Sistem informasi penanggulangan adalah sebuah sistem informasi yang digunakan untuk membantu bagian dinas terkait, peternak dan masyarakat umum untuk mengurangi dampak penyebaran wabah serta mengurangi kemungkinan terjadinya penyebaran penyakit di wilayah tertentu. Maka dari itu efektivitas dan kemudahan sebuah sistem informasi akan sangat diperlukan agar sistem informasi dapat digunakan dengan mudah dan memberikan informasi yang dapat digunakan untuk mengurangi dampak buruk penyebaran penyakit ternak serta penanganannya.

\section{METODE PENELITIAN}

\subsection{Prosedur Penelitian}

\subsubsection{Studi Literatur}

Pencarian buku-buku penunjang sistem informasi yang ada, teori-teori sistem, dan usulan yang dikutip dari orang-orang yang berkompeten. Dan juga dengan mengumpulkan referensi berupa buku-buku, skripsi, jurnal maupun tulisan-tulisan yang dimuat di situs web mengenai penyebaran dan penanganan penyakit unggas.

\subsubsection{Pengumpulan Data}

Penelitian ini menggunakan beberapa metode dalam pengumpulan data yaitu:

a. Metode wawancara (interview)

Metode ini merupakan pengumpulan data dengan wawancara langsung dengan pihak dari dinas terkait mengenai penyebaran dan penanganan penyakit unggas. 
b. Dokumen

Pengumpulan data dokumen dilakukan dengan meminta data kepada dinas terkait mengenai penyebaran dan penanganan penyakit unggas.

\subsubsection{Analisa Kondisi Sistem Informasi Penanggulangan Penyebaran Penyakit pada Ternak Unggas}

Sistem informasi pengumpulan data penyakit unggas yang digunakan kesehatan hewan saat ini adalah aplikasi sederhana yang dibuat menggunaan Microsoft Access dan Excel. Data masukan adalah data yang dikirim setiap bulannya oleh dinas peternakan kabupaten lalu dimasukan lagi oleh pegawai bagian kesehatan hewan dinas provinsi. Dengan sistem seperti ini penanganan serta pendataan terhadap penyebaran penyakit cenderung memerlukan waktu yang lama mengingat harus menunggu waktu rekapitulasi data yang dilakukan disetiap akhir bulan.

\subsubsection{Perancangan Sistem Infomasi}

Pada tahap ini akan dilakukan perancangan sistem berdasarkan dari hasil analisa sistem, hasil wawancara user sistem dan hasil dari observasi. Tahap ini bertujuan memberikan gambaran mengenai alur kerja sistem. Perancangan yang dilakukan diantaranya:

a. Perancangan alur kerja sistem

Perancangan alur kerja sistem merupakan proses perancangan alur kerja dalam sistem yang dibuat dengan seksama agar kerja sistem tidak bermasalah atau sesuai dengan harapan. Perancangan alur kerja sistem dijelaskan dengan Activity Diagram dan Use Case Diagram.

b. Perancangan basis data

Perancangan basis data pada sistem informasi ini dibuat dengan perancangan entitas atau biasa disebut dengan Entity Relationship dan diperjelas dengan penjabaran tabel.

\subsubsection{Pengembangan Aplikasi}

Tahap ini bertujuan untuk mengimplemtasikan sistem berdasarkan hasil perancangan sistem. Pengembangan aplikasi yang dilakukan yaitu:

a. Pembuatan Database

Pembuatan database pada Sistem Informasi penyebaran penyakit ternak unggas di provinsi Kalimantan Selatan dan database penyakit unggas beserta penangannya menggunakan MySql.

b. Coding

Pengerjaan coding pada Sistem Informasi penyebaran penyakit ternak unggas di provinsi Kalimantan Selatan menggunakan bahasa pemrograman PHP.

c. Testing

Testing merupakan tahapan untuk mengetahui apakah program yang dibuat sudah sesuai dengan spesifikasi dari tahap perancangan sistem infomasi. Apabila ada kesalahan pada program akan diperbaiki kembali sampai hasil sesuai dengan yang diharapkan. 


\subsubsection{Pengukuran Efisiensi}

Maksud dari pengukuran ini adalah mengukur tingkat efisiensi sistem informasi yang saat ini digunakan dengan sistem informasi yang sedang dikembangkan. Cara pengukuran dapat dilakukan dengan metode usability testing.

\subsubsection{Usability Testing}

Definisi usability adalah sejauh mana suatu produk dapat digunakan oleh pengguna tertentu untuk mencapai target yang ditetapkan dengan efektivitas, efesiensi dan mencapai kepuasan penggunaan dalam konteks tertentu. Konteks penggunaan terdiri dari pengguna, tugas, peralatan (hardware, software dan material). Berdasarkan definisi tersebut usability diukur berdasarkan komponen :

a. Kemudahan (learnability) didefinisikan seberapa cepat pengguna mahir dalam menggunakan sistem serta kemudahan dalam penggunaan menjalankan suatu fungsi serta apa yang pengguna inginkan dapat meraka dapatkan.

b. Efisiensi (efficiency) didefinisikan sebagai sumber daya yang dikeluarkan guna mencapai ketepatan dan kelengkapan tujuan.

c. Mudah diingat (memorability) didefinisikan bagaimana kemampuan pengguna mempertahankan pengetahuannya setelah jangka waktu tertentu, kemampuan mengingat didapatkan dari peletakkan menu yang selalu tetap.

d. Kesalahan dan keamanan (errors) didefinisikan berapa banyak kesalahankesalahan apa saja yang dibuat pengguna, kesalahan yang dibuat pengguna mencakup ketidaksesuaian apa yang pengguna pikirkan dengan apa yang sebenarnya disajikan oleh sistem.

e. Kepuasan (satisfaction) didefinisikan kebebasan dari ketidaknyamanan, dan sikap positif terhadap penggunaan produk atau ukuran subjektif sebagaimana pengguna merasa tentang penggunaan sistem.

\section{HASIL DAN PEMBAHASAN}

\subsection{Analisis Sistem}

\subsubsection{Gambaran Umum Sistem}

Sistem informasi ini adalah sistem informasi berbasis web yang dapat membantu kerja pegawai bagian kesehatan hewan dan para peternak unggas bisa mengetahui dimana saja terjadi penyebaran penyakit unggas yang sedang menyerang. Sistem ini berguna menampilkan informasi tentang penyebaran penyakit unggas dari dinas peternakan provinsi Kalimantan Selatan agar penyebaran dapat dikontrol oleh pihak dinas maupun peternak unggas di Kalimantan Selatan. 


\subsubsection{Analisis Input dan Ouput}

Analisa yang dilakukan menghasilkan kebutuhan input dan output guna mendukung sistem informasi ini. Berikut ini input dan output yang dibutuhkan yaitu

a. Input Data Wilayah

Data wilayah merupakan data wilayah yang menjadi tanggung jawab

pengawasan dari dinas peternakan provinsi Kalimantan Selatan yang mana dapat menjadi area penyebaran penyakit unggas.

b. Input Data Penyakit

Data penyakit merupakan data jenis-jenis penyakit yang dapat menjangkit ternak unggas.

c. Input Data Spesimen

Data spesimen adalah data jenis sampel yang dapat diperiksakan untuk mengetahui jenis penyakit unggas.

d. Input Data Pemeriksaan

Data pemeriksaan adalah data dimana dilakukan pemeriksaan terhadap sampel maupun area yang dianggap telah terjangkit masalah penyakit unggas.

e. Input Data Permohonan

Data permohonan adalah data informasi tentang permohon untuk dilakukan pemeriksaan sampel atau lokasi yang dianggap memiliki masalah penyakit unggas.

Sedangkan output program adalah pemetaan dan pengolahan data penyebaran penyakit unggas yang tersebar di daerah Kalimantan Selatan.

\subsection{Perancangan Sistem}

\subsubsection{Perancangan Proses}

Perancangan sistem digunakan untuk menggambarkan apa yang bisa dilakukan oleh sebuah sistem. Pada perancangan proses menggunakan Activity Diagram yang bertujuan untuk mengetahui jalur aktivitas pada sistem, dari aktivitas dimulai sampai aktivitas berhenti. Berikut ini merupakan perancangan proses dari sistem dengan menggunakan Activity Diagram :

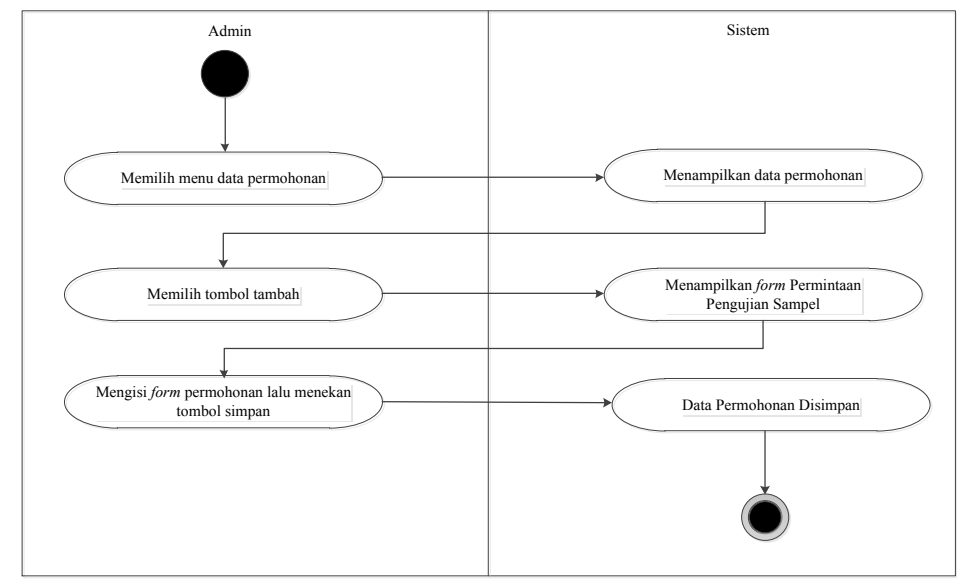

Gambar 1. Activity Diagram Data Permohonan 


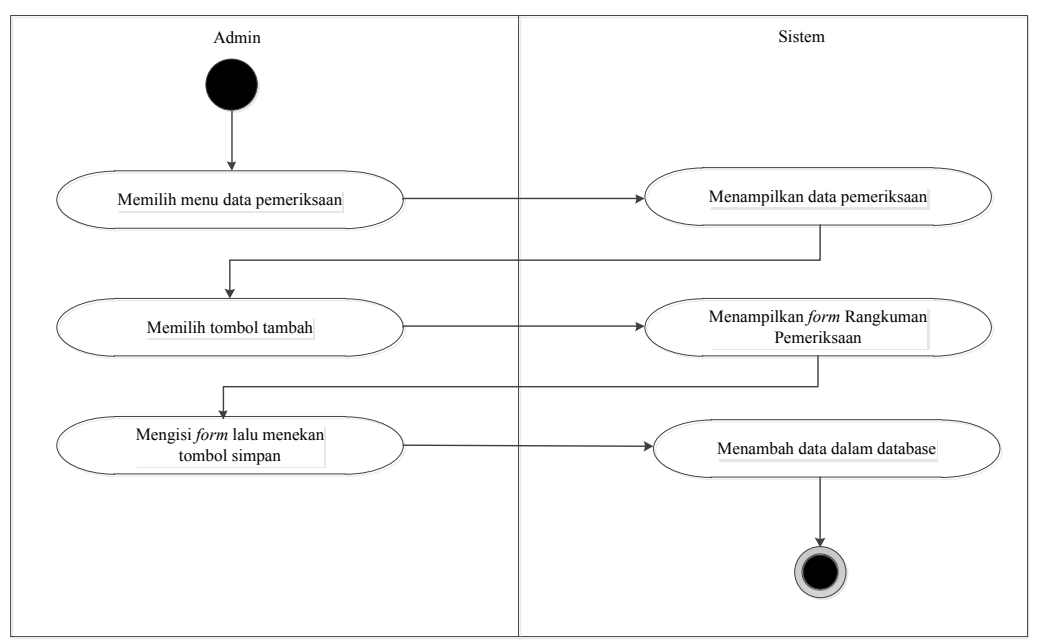

Gambar 2. Activity Diagram Data Pemeriksaan

\subsubsection{Perancangan Basis Data}

Perancangan database dengan menggunakan ERD (Entitas Relationship Diagram) untuk menggambarkan hubungan antar entitas.

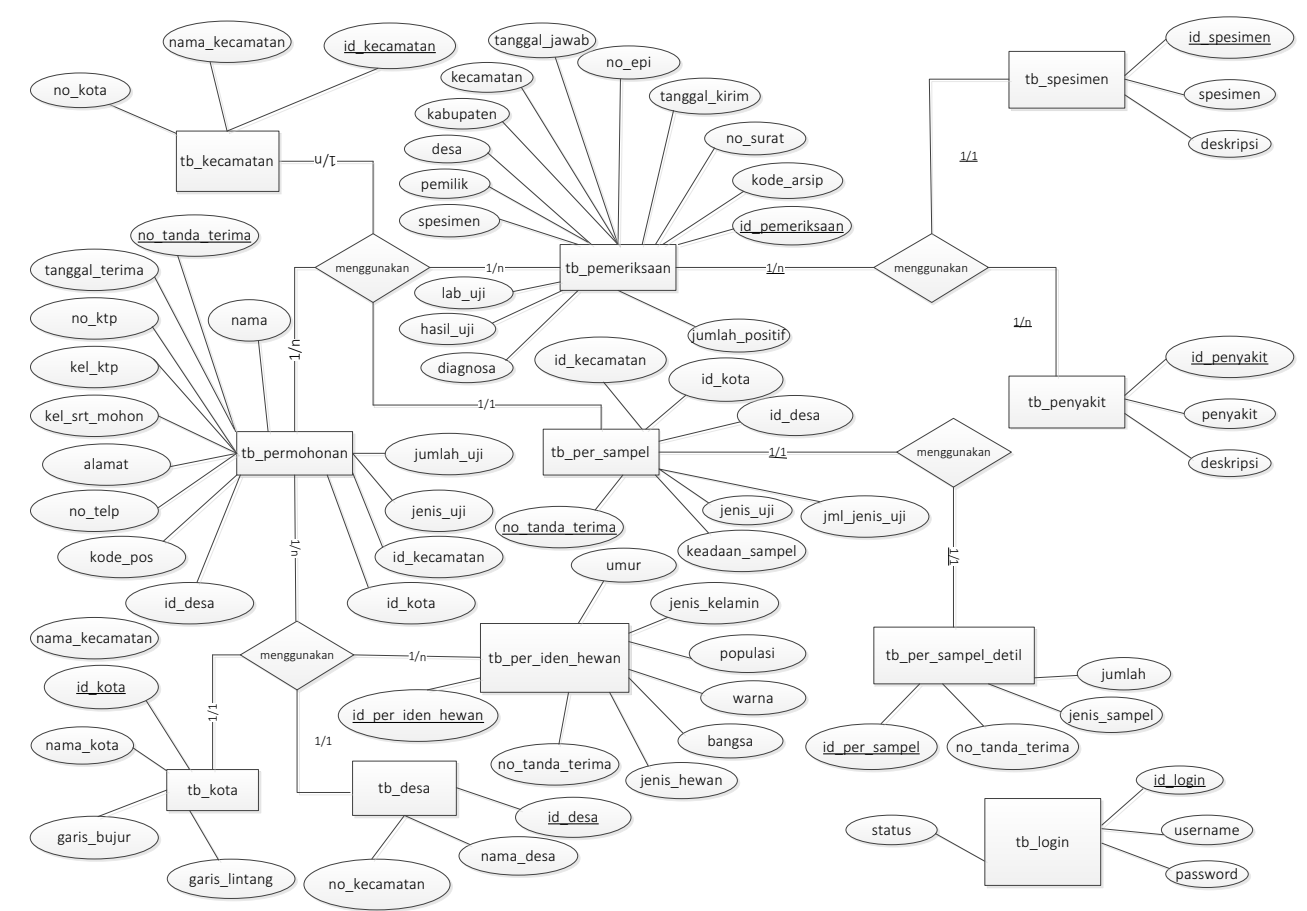

Gambar 3. ERD (Entitas Relationship Diagram) 


\subsection{Pengembangan Aplikasi}

\subsubsection{Form Halaman Utama}

Menu home adalah halaman utama sistem informasi ini, pada halaman ini terdapat gambar peta sebagai background dan menu bar diatasnya untuk menuju menu yang ingin dipilih.

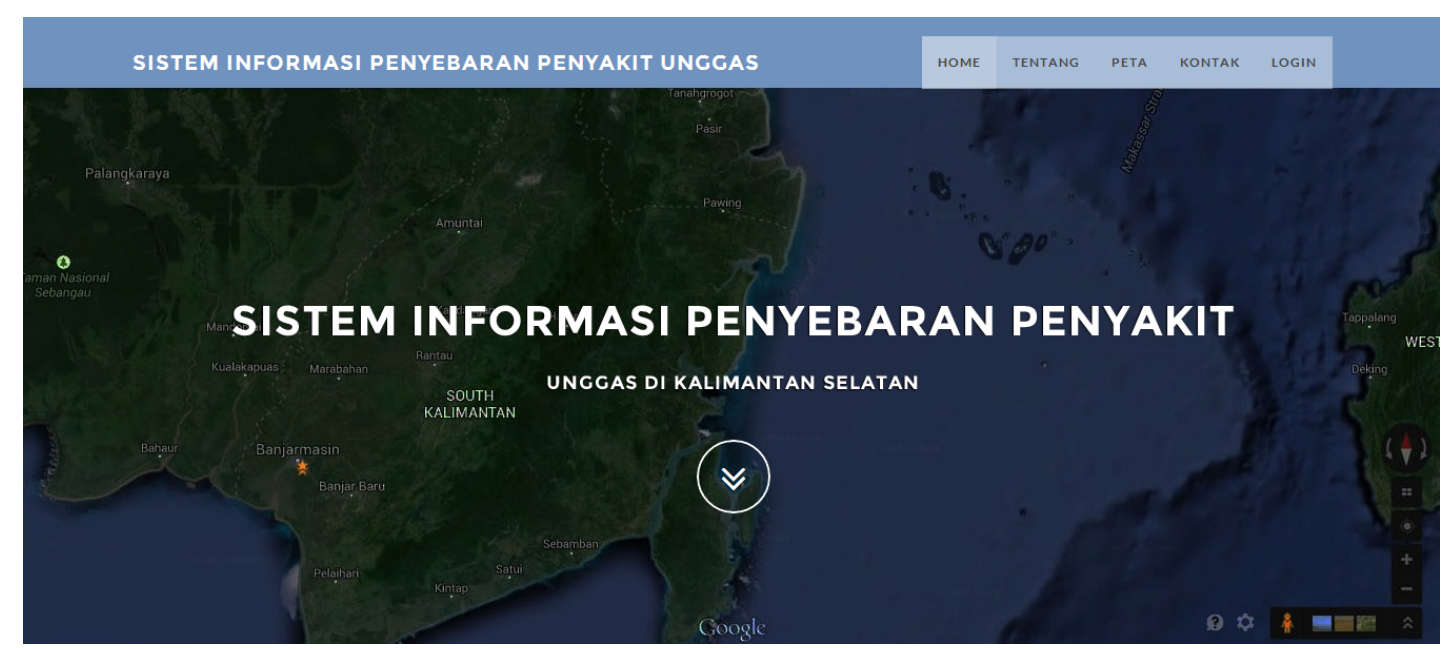

Gambar 4. Halaman Utama

\subsubsection{Form Halaman Login}

Menu login merupakan halaman dimana user dapat masuk sebagai administrator yang dapat mengelola data seperti menambah, merubah dan menghapus data yang ada pada sistem informasi dengan memasukkan username dan password sebagai administrator.

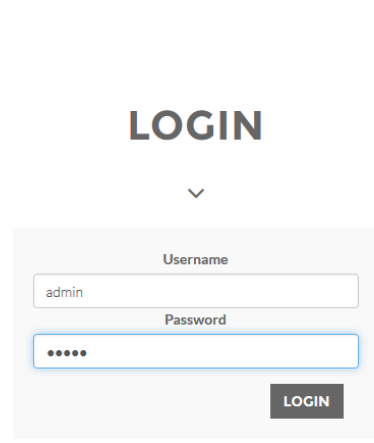

Gambar 5. Form Halaman Login 


\subsubsection{Form Data Permohonan}

Menu data permohonan adalah halaman yang berisikan tentang data permohonan pemeriksaan dari peternak unggas maupun pegawai dinas.



Gambar 6. Form Data Permohonan

\subsubsection{Form Data Pemeriksaan}

Menu data pemeriksaan adalah halaman yang berisikan data hasil pemeriksaan yang telah dilakukan terhadap spesimen yang telah diperiksa.

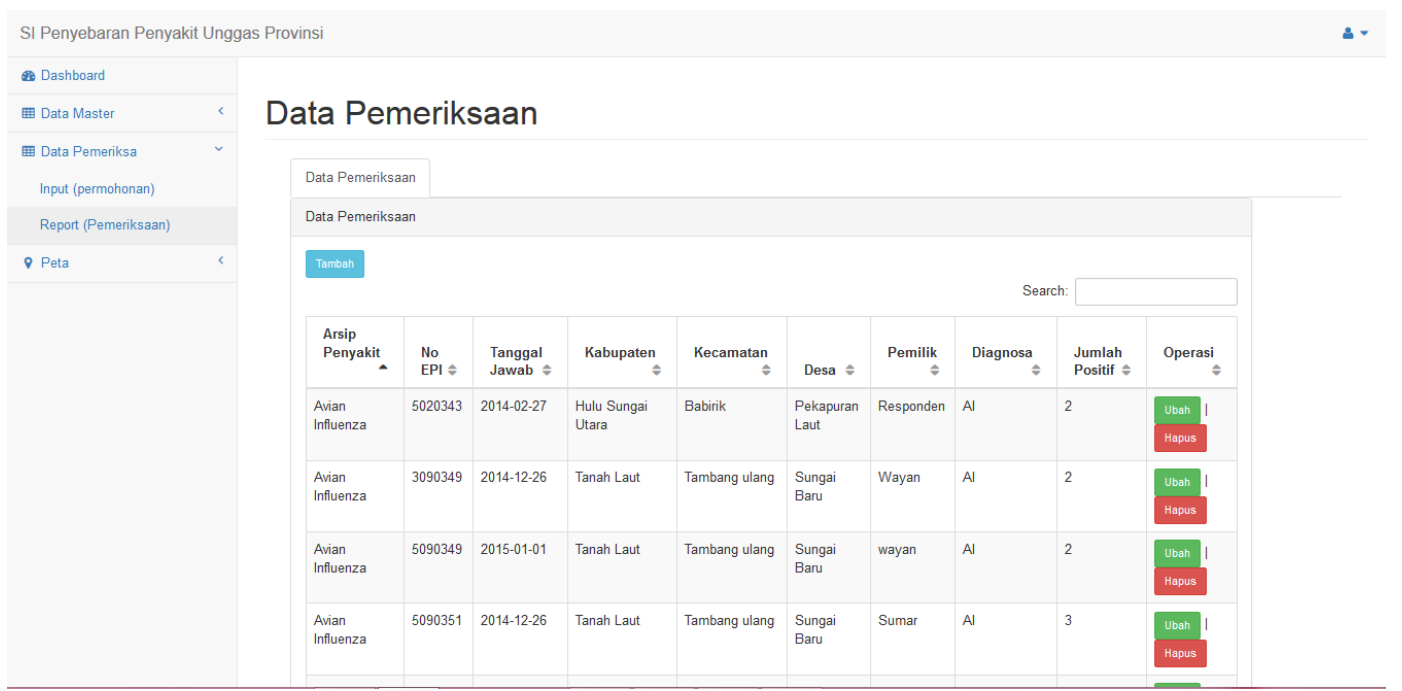

Gambar 7. Form Data Pemeriksaan

\subsubsection{Form Peta Permohonan}

Halaman peta permohonan adalah halaman yang digunakan untuk menampilkan permohonan pemeriksaan dari peternak berada di Kalimantan Selatan. 


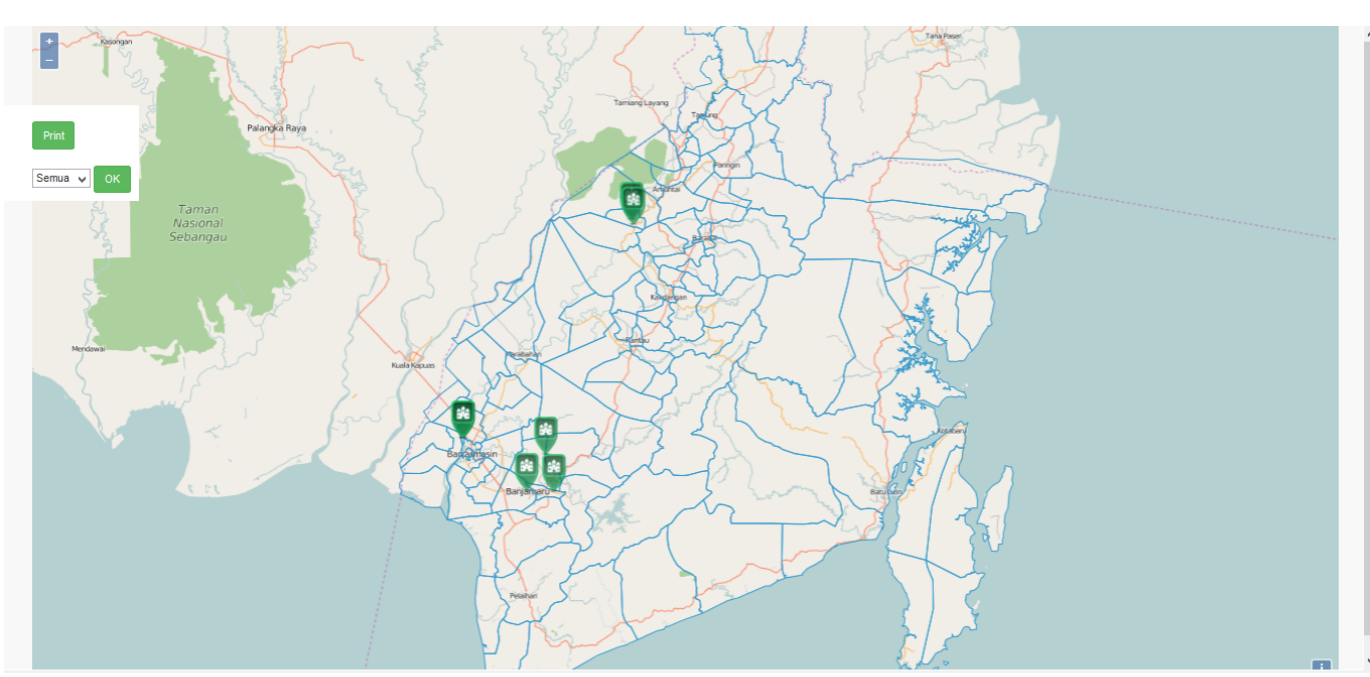

Gambar 8. Peta Permohonan

\subsubsection{Form Peta Sebaran Penyakit}

Halaman peta sebaran penyakit adalah halaman yang digunakan untuk menampilkan persebaran penyakit unggas yang berada di Kalimantan Selatan.

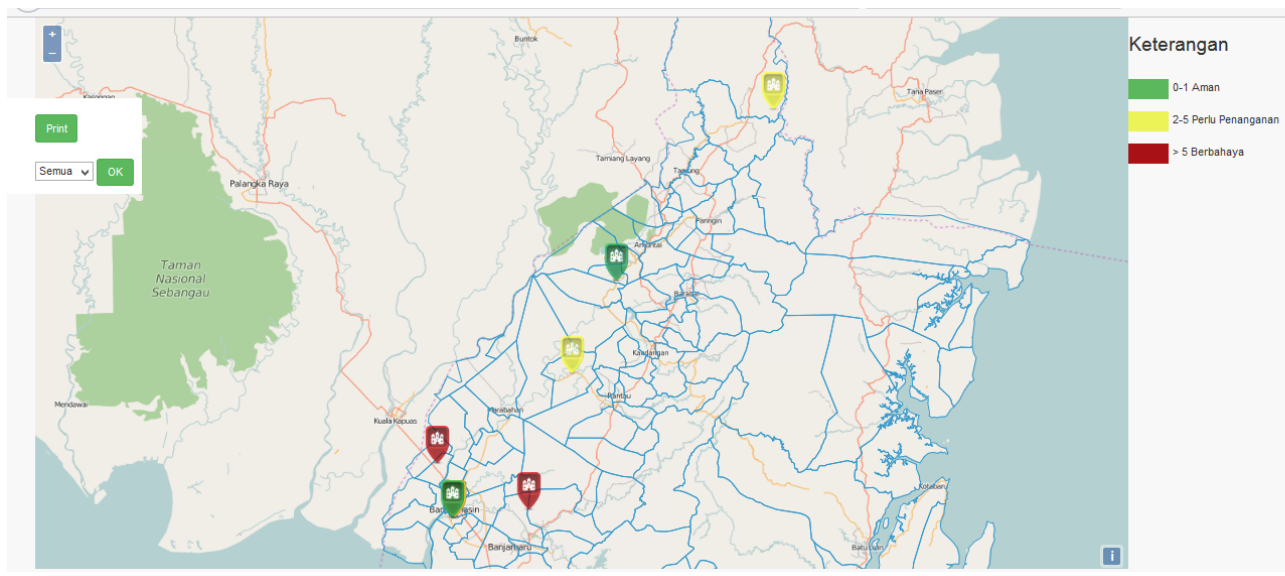

Gambar 9. Peta Pemeriksaan

\subsection{Pengujian Aplikasi}

\subsubsection{Pengujian Kemampuan Web}

Pada pengujian ini pilihan jenis tes adalah klik. Maksud dari click itu sendiri adalah menjalankan tes dengan beban konstan sampai setiap pengguna telah menghasilkan sejumlah tertentu klik. 


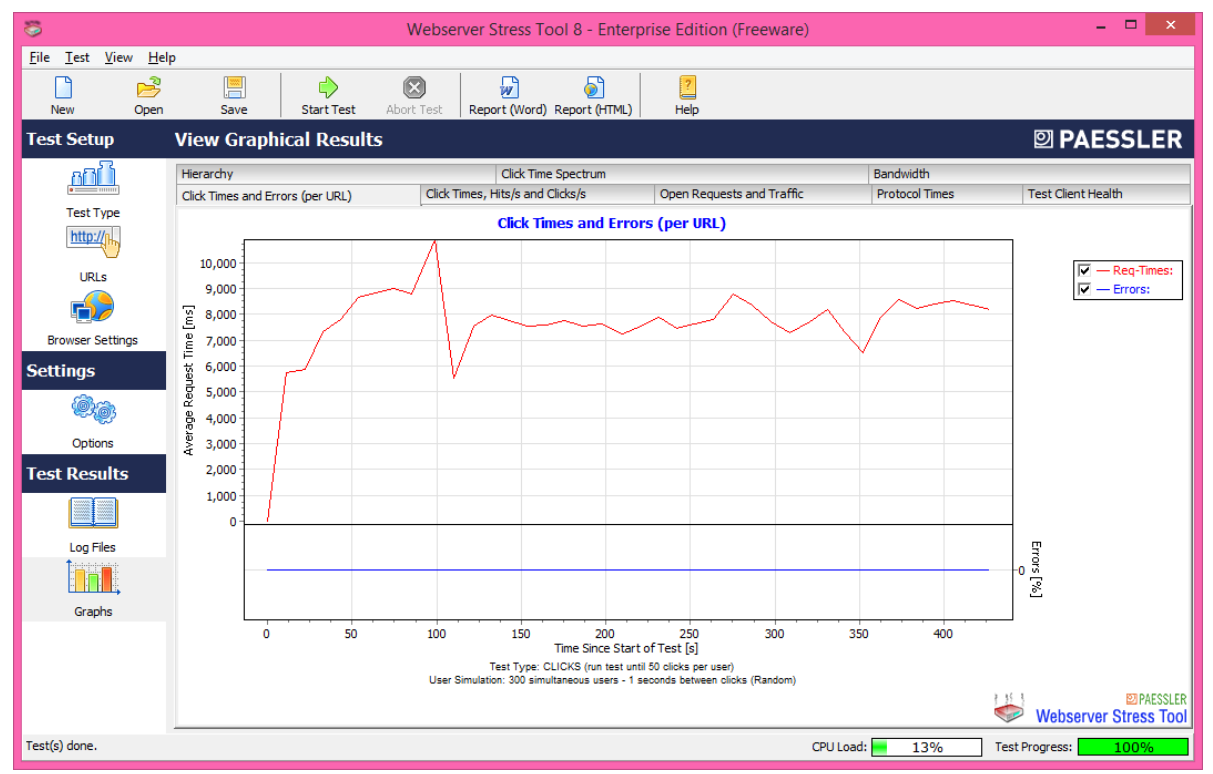

Gambar 10. Hasil pengukuran dengan Click

Pada pengujian selanjutnya pilihan jenis tes adalah waktu. Maksud dari time itu sendiri adalah menjalankan tes dengan beban konstan untuk waktu tertentu.

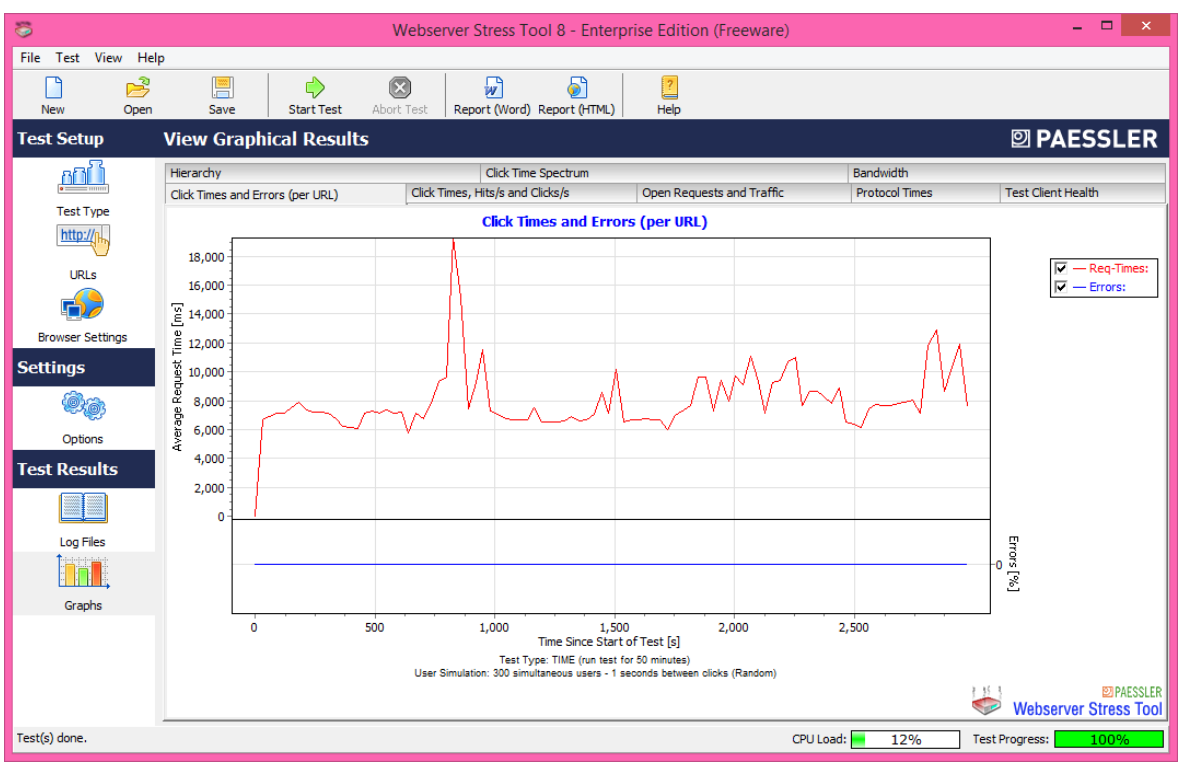

Gambar 11. Hasil pengukuran dengan Time

\subsection{Pengujian Database}

Pada pengujian database kali ini saya menggunakan aplikasi Mysqlslap. Dari hasil pengujian database yang didapatkan akan saya jabarkan pada gambar 12 dan Gambar 13 di bawah ini: 


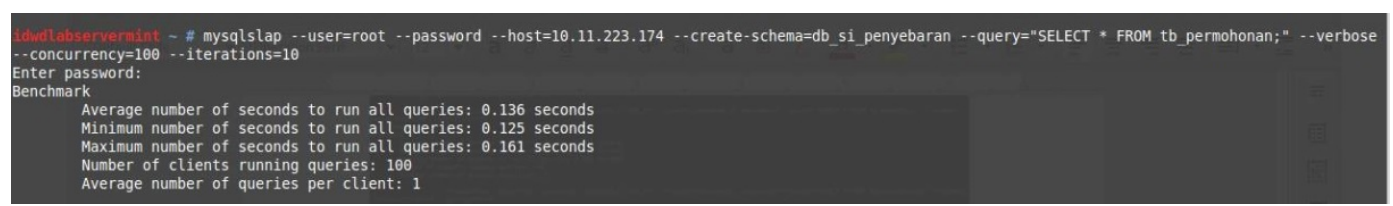

Gambar 12. Hasil Pengujian Database Pemeriksaan

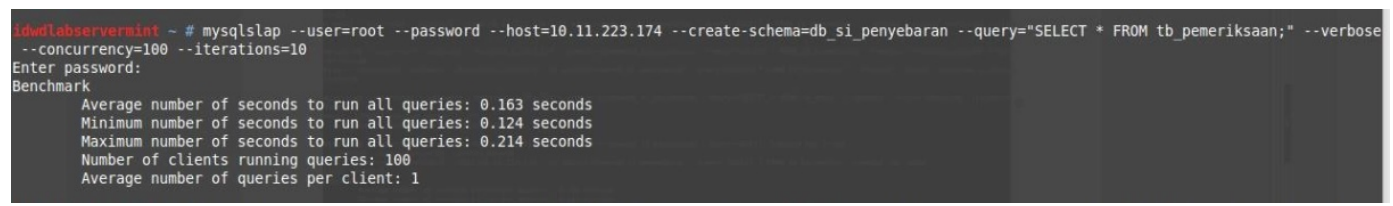

Gambar 13. Hasil Pengujian Database Pemeriksaan

\subsection{Pengujian Keamanan}

Pada pengujian keamanan kali ini saya menggunakan aplikasi Acunetix Web Vulnerability Scanner 9, dari aplikasi ini terdapat 217 celah keamanan yang terdiri dari 6 tingkat tinggi, 149 tingkat sedang dan 15 tingkat rendah. Yang akan saya jabarkan pada gambar di bawah ini :

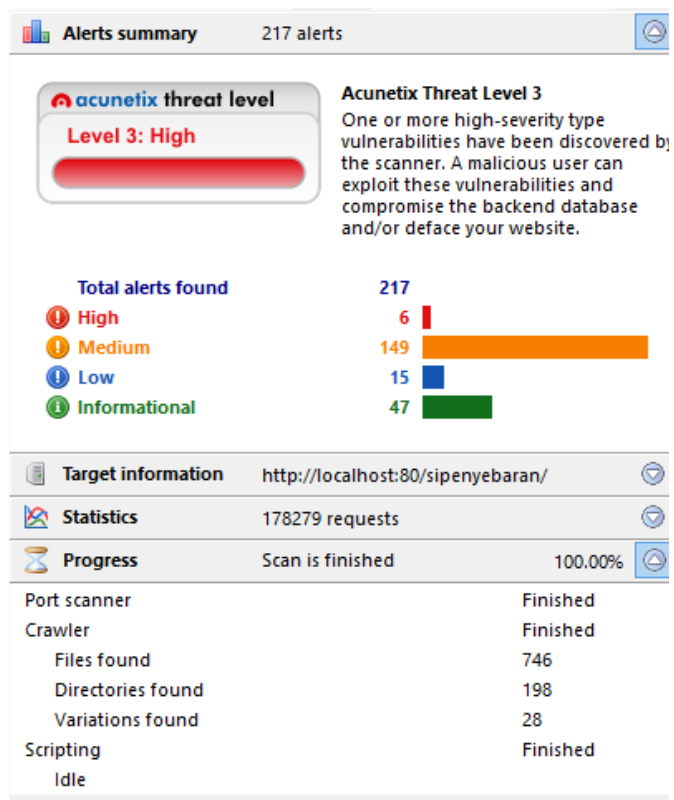

Gambar 14. Hasil Scan Menggunakan Acunetix Web Vulnerability Scanner 9 


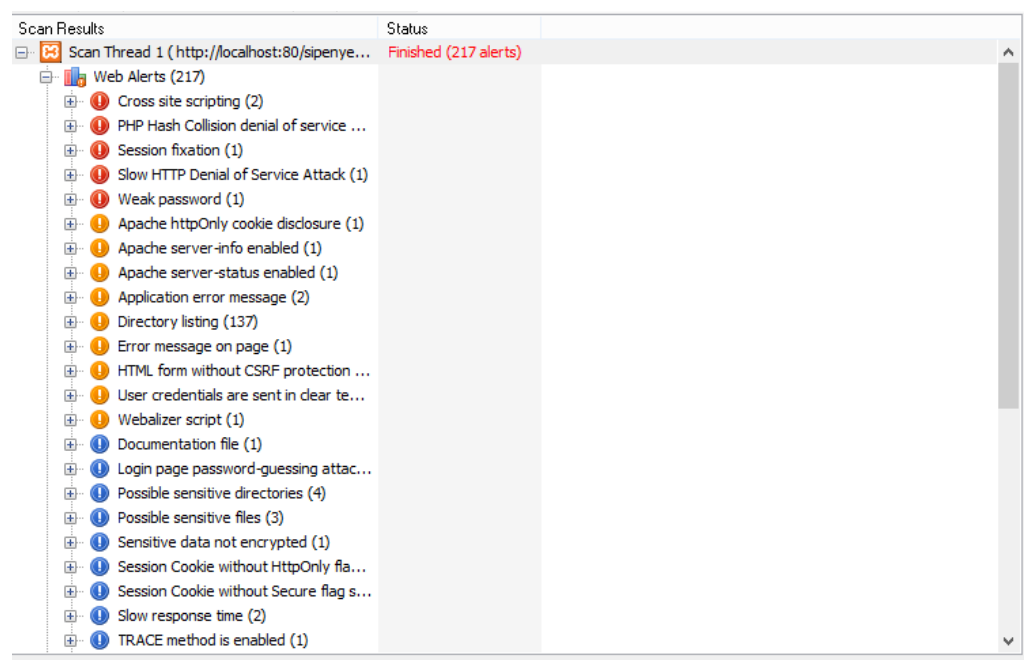

Gambar 15. Celah - celah yang terditeksi

\subsection{Pembahasan}

Sistem pemetaan dengan sistem infomasi geografis diterapkan pada sistem informasi ini agar menambahkan kemudahan dalam melakukan pemetaan lokasi penyebaran penyakit unggas. Fitur pemetaan sendiri dihubungkan dengan fitur permohonan dan fitur pemeriksaan. Pada fitur permohonan akan terlihat data permohonan para peternak, sedangkan fitur pemeriksaan akan terlihat lokasi terjangkit penyakit dan dapat langsung dipetakan dan ditampilkan.

Untuk hasil pengujian kemampuan web, tipe yang diuji oleh aplikasi berupa Click dan Time. Dari hasil yang didapatkan tidak ditemukan error saat dilakukannya pengujian, pengujian itu sendiri dilakukan dengan 300 pengguna dan berjalan sampai 50 klik setiap penggunanya.

Database yang digunakan untuk pengujian sistem informasi ini adalah database keseluruhan dalam sistem ini. Dan hasil dari pengujian yaitu rata-rata jumlah detik untuk menjalankan semua pertanyaan 0.276818 detik, jumlah minimum detik untuk menjalankan semua pertanyaan 0.220182 detik dan jumlah maksimum detik untuk menjalankan semua pertanyaan 0.291182 detik.

Dan pada pengujian keamanan, dari aplikasi ini terdapat 217 celah keamanan yang terdiri dari 6 tingkat tinggi, 149 tingkat sedang dan 15 tingkat rendah. Dan rata-rata yang didapatkan dari kuesioner untuk kemudahan, mudah diingat dan kepuasan sebanyak $85 \%$.

Dilihat melalui kuesioner diatas sistem ini memberikan manfaat buat pengguna yang menggunakan, dan kemampuan web bisa dikatakan baik karena tidak ditemukan error saat pengujian, pengujian database cukup baik, hanya saja di pengujian keamanan terdapat beberapa celah yang terdeteksi. Sehingga berdasarkan komponen Usability. 


\section{SIMPULAN}

Tingkat efisien dan kemudahan sistem ini berdasarkan pengujian kemampuan terhadap komponen Usability telah terpenuhi yaitu sebagai berikut:

a. Kemudahan (learnability), terdapat pada kuesioner dengan rata-rata 85\%.

b. Efisiensi (efficiency), terdapat pada webstress yaitu Click dengan rata-rata 7,804ms, sedangkan Time dengan rata-rata 7,704ms. Dan database set yaitu rata-rata jumlah detik untuk menjalankan semua pertanyaan 0.276818 detik, jumlah minimum detik untuk menjalankan semua pertanyaan 0.220182 detik dan jumlah maksimum detik untuk menjalankan semua pertanyaan 0.291182 detik.

c. Mudah diingat (memorability), terdapat pada kuesioner dengan rata-rata $85 \%$.

d. Kesalahan dan keamanan (errors), terdapat pada keamanan test. Dari hasil pengujian terdapat 217 celah keamanan yang terdiri dari 6 tingkat tinggi, 149 tingkat sedang dan 15 tingkat rendah.

e. Kepuasan (satisfaction), terdapat pada kuesioner dengan rata-rata 85\%.

\section{DAFTAR PUSTAKA}

[1] Jogiyanto HM, "Sistem Informasi Keperilakuan, edisi Revisi", Yogyakarta. ANDI, 2007

[2] Nahdhatuzzahra, “Peningkatan Efisiensi dan Kemudahan dalam Penanggulangan Penyebaran Penyakit pada Ternak Unggas dengan Sistem Informasi Berbasis Web", Skripsi Program Studi Ilmu Komputer, Universitas Lambung Mangkurat, Banjarbaru, 2016.

[3] Mardiasmo, “Akuntansi Sektor Publik”, Yogyakarta. Andi, 2002. 